\title{
APROVEITAMENTO DE ÁGUA PLUVIAL: CAPTAÇÃO E UTILIZAÇÃO PARA FINS NÃO POTÁVEIS EM UMA RESIDÊNCIA DE ALTO PADRÃO NA CIDADE DE JUIZ DE FORA - MG
}

\author{
Henrique da Silva Pizzo ${ }^{1}$ \\ Jessica Gomes Ferrari² \\ Lucas de Souza Mauricio ${ }^{3}$ \\ Thalita Batista de Oliveira Arbex ${ }^{4}$
}

\begin{abstract}
RESUMO: A água é um recurso essencial para a humanidade e para o desenvolvimento socioeconômico. Este recurso sempre foi considerado um bem abundante na natureza, como consequência deste fato, foi explorado sem a preocupação com a sua possível falta. $\mathrm{O}$ rápido e desordenado crescimento populacional, o qual gera um aumento significativo na demanda do uso de água potável, é um dos fatores que contribuiu para que viessem à tona preocupações com a falta de água no mundo. Com isso, cada vez mais, se faz necessário a busca por práticas sustentáveis, que é uma forma para otimizar os recursos hídricos. Com a finalidade de analisar a eficiência de um sistema de aproveitamento de água pluvial, bem como a potencial economia gerada, o presente trabalho por meio de uma revisão bibliográfica, apresenta um breve resumo sobre o histórico da água e a sua importância, o aproveitamento do uso de água pluvial, e onde podem ser aplicadas, abordando ainda questões como a conscientização ambiental, e a escassez de água no mundo. E além disso, fornece o estudo de uma das técnicas de aproveitamento de água pluvial para fins não potáveis, com a implementação desta técnica em uma residência familiar, localizada em Juiz de Fora (MG), mediante um estudo de caso. O sistema de aproveitamento de água é bastante benéfico, a não utilização de água potável em atividades que não demandam um controle de alta qualidade, traz retornos significativos tanto para o meio ambiente, quanto para o fator econômico.
\end{abstract}

Palavras-chave: Água. Escassez. Valor. Aproveitamento.

ABSTRACT: Water is an essential resource for humanity and for socioeconomic development. This resource has always been considered an abundant good in nature, as a result of this fact, it was explored without concern for its possible lack. The rapid and

\footnotetext{
r Doutor em Engenharia Civil pela UNICAMP. Centro Universitário Estácio Juiz de Fora. Companhia de Saneamento Municipal de Juiz de Fora. E-mail: henriquepizzo.estacio@gmail.com.

${ }^{2}$ Engenheira Civil pelo Centro Universitário Estácio Juiz de Fora.E-mail: jessicagferrari@yahoo.com.br.

3 Acadêmico em Engenharia Civil pelo Centro Universitário Estácio Juiz de Fora. E-mail: lucasdesouzatec@gmail.com.

4 Bacharel em Turismo pela Universidade Federal de Juiz de Fora e Engenheira Civil pelo Centro Universitário Estácio Juiz de Fora. Thalitaarb. E-mail: ex@gmail.com
} 
disorderly population growth, which generates a significant increase in the demand for the use of drinking water, is a factor that contributed to the emergence of concerns about the lack of water in the world. With this, it is increasingly necessary to search for sustainable practices, which is a way to optimize water resources. In order to analyze the efficiency of a rainwater harvesting system, as well as the potential savings generated, the present work, through a literature review, presents a brief summary of the history of water and its importance, the use of rainwater, and where they can be applied, also addressing issues such as environmental awareness, and water scarcity in the world. In addition, it provides the study of one of the techniques for using rainwater for non-drinking purposes, with the implementation of this technique in a family home located in Juiz de Fora (MG), through a case study. The water use system is quite beneficial, not using potable water in activities that do not require high quality control, brings significant returns both for the environment and for the economic factor.

Keywords: Water. Exploitation. Rain. Scarcity. Value.

\section{INTRODUÇÃO}

A água, como recurso natural e vital para a preservação da vida sobre a Terra, tem sido negligenciada pelo rápido e desordenado crescimento populacional o qual gera cada vez mais a sua demanda, de forma que é possível observar que ela sempre fez parte de todo o desenvolvimento socioeconômico. Essa demanda pelo consumo traz à tona a preocupação com sua escassez, sendo assim, surge a busca de alternativas para o seu aproveitamento e seu uso sustentável. O presente artigo pretende retratar umas das técnicas de seu aproveitamento como alternativa para equacionar a relação de oferta $\mathrm{x}$ demanda de água, por meio do aproveitamento pluvial em residências. Essa maneira possibilita a captação da água da chuva levada para um reservatório, através de alguns componentes, atendendo, desta forma, ao consumo para fins não potáveis.

Para tanto, parte-se do pressuposto de que a viabilidade deste sistema é dependente de alguns fatores, tais como a precipitação, desperdício, área de captação, como será observado no decorrer deste artigo. Assim, o presente trabalho visa responder à seguinte questão-problema: as atuais técnicas de reaproveitamento de água são realmente eficazes?

Para viabilizar este trabalho, serão realizados uma revisão bibliográfica relacionada ao tema, bem como um estudo de caso da implementação da técnica de aproveitamento de água em residência, anteriormente relatada. Isto posto, para cumprir este direcionamento, o trabalho contará com uma breve introdução sobre o histórico e a importância da água, abarcando as questões de conscientização ambiental, bem como 
seu "valor" e sua escassez. Num segundo momento, o trabalho pretende debruçar-se sobre o aproveitamento da água pluvial, passando pelo seu histórico de aproveitamento, ao revisitar técnicas e estatísticas de variadas regiões do Brasil e do mundo. Por fim, será realizado o estudo de caso que culminará no enlace das teorias e das práticas abordadas no trabalho, para, finalmente, se chegar às considerações finais.

\section{HISTÓRICO E IMPORTÂNCIA DO “BEM” ÁGUA}

Segundo a Escola Britannica ${ }^{5}$, desde o princípio da história da humanidade, a água é vista como um recurso dotado de inúmeras vantagens, haja vista que as primeiras civilizações se formaram em vales de rios. Como exemplo, pode-se citar a civilização dos sumérios - a primeira da qual se tem registros - a qual foi fundada em torno dos rios Tigre e Eufrates. Uma das vantagens de se instalarem ao redor de rios está relacionada ao cultivo de produtos para sobrevivência própria e de todo o restante da civilização, já que, nesses locais, se encontram solos férteis para o plantio. Além disso, podem-se notar vários outros benefícios de se ter a água por perto, como o uso para o consumo (próprio e dos animais), o preparo de alimentos, a higienização pessoal e, até mesmo, a obtenção de alimentos, como é o caso da pesca.

Outro ponto de grande destaque para os recursos hídricos é a sua íntima relação com a saúde, expressa, inclusive, no slogan "água é vida”. Entretanto, para que seja verídica tal afirmação, faz-se necessário que a água esteja própria para consumo, evitando, dessa maneira, doenças por contaminações. Nesse sentido, em se tratando de saneamento básico, é preciso de um controle, para que não haja a proliferação de pragas que gerem doenças, como ocorreu, historicamente, no Brasil, nos primeiros anos do século $\mathrm{XX}$, quando houve uma mudança radical no quesito saneamento na cidade do Rio de Janeiro, como uma das medidas para sanar a epidemia de varíola que controlava a cidade. ${ }^{6}$ Quanto a sua ocorrência, a maior parte da superfície terrestre é coberta de água, um recurso de fundamental importância, pois esta é essencial fonte de vida.

ESCOLA BRITANNICA. Civilização. Disponível em: <https://escola.britannica.com.br/artigo/civiliza\%C3\%A7\%C3\%A30/480992\#: :text=As\%2ociviliza\% $\mathrm{C}_{3}$

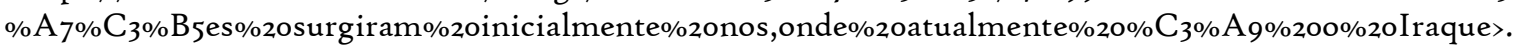
Acesso em: 22 abr 2021.

6 BEZERRA, Juliana. Revolta da Vacina. In: TODA MATÉRIA, s./d. Disponível em: <https://www.todamateria.com.br/revoltadavacina/\#: :text=A\%2oRevolta\%2oda\%2oVacina\%2ofoi,Janei ro\%2C\%2oem\%2onovembro\%2ode\%201904>. Acesso em 22 abr 2021. 
Segundo Thomas (200I), "sabe-se que que 2/3 da superfície terrestre é coberta por água, mas desse total, menos de o,o6\% é de água apropriada para o consumo usa o humano" (apud Siqueira Campos, p.12, 2004). Utilizada, desde sempre, no desenvolvimento socioeconômico da humanidade, ela é fator necessário para os processos de produção, desenvolvimento, comunicação e de vida.

Como destacado por (SOUZA et al, 2016):

A água por ser considerada um bem indispensável à humanidade, deve ser preservada, cabendo à sociedade adotar medidas sustentáveis, uma vez que a falta deste recurso pode dar origem a graves problemas mundiais, afetando de forma direta a sobrevivência humana. (apud GOMES, 2018, p.4).

\section{3 ÁGUA COMO PRODUTO DOTADO DE VALOR}

A água é um recurso imprescindível para a humanidade. Assim, faz-se necessário reconhecer que ela é um bem econômico e um recurso estratégico essencial ao desenvolvimento socioeconômico dos países. No entanto, nunca se teve tanta preocupação com relação à sua possível falta, ainda que haja sua grande disponibilidade no mundo, inquietação essa que vem sendo muito debatida já há algumas décadas.

É possível abstrair que, no mundo atual, existe uma espécie de "balança" que determina o quão importante e valioso é determinado produto. Nesse aspecto, quanto mais abundante, menos valor se é dado, e, do contrário, quanto mais escasso, mais valor se tem. Nessa mesma linha de raciocínio, encaixa-se a questão da água, um recurso com tanta importância, porém com uma taxa de disponibilidade (da sua forma considerada potável) em queda, devido especialmente a sua má utilização.

A água é também o principal recurso utilizado na agricultura, de maneira que influencia diretamente na produção e na qualidade dos produtos agrícolas, cujo valor de mercado, por sua vez, será determinado, sobretudo, com relação ao valor das importações e exportações de um produto, o qual pode estar em falta, por conta da seca, por exemplo. A água, portanto, é ponto determinante. Tendo em vista que esse recurso potável exerce grande influência econômica, conforme observado na agricultura, bem como na indústria, na pecuária e para a manutenção da sobrevivência humana, no Simpósio de Sustentabilidade e Contemporaneidade nas Ciências Sociais, foi destacada a sua importância, como se pode notar a segui. Segundo Selander e Valdivia (2005): 
Diante do aumento da população mundial, das mudanças climáticas e da intervenção crescente do homem nos recursos naturais, os principais objetivos do aproveitamento de água da chuva são: alertar a população sobre a importância de economizar e reservar água por ser um recurso finito; minimizar o escoamento do alto volume de água nas redes pluviais durante as chuvas fortes; utilizar a água para fins não potáveis, como irrigação dos jardins, lavagens de calçadas, carros, máquinas e descargas de vaso sanitário; economia na conta de água; ter uma reserva para possíveis casos de falta de água da concessionária, entre outros (apud ZATTA et al, 2018, p. 4).

Desta forma, com o aumento da demanda, faz-se necessário um controle maior para a sua utilização racional e sustentável.

\section{I CONSCIENTIZAÇÃO AMBIENTAL}

A conscientização consiste em compreender o meio em que se vive, refletir sobre as responsabilidades que se adquire com relação às próprias ações, as quais, com o tempo, podem causar impactos positivos e/ou negativos.

A conscientização ambiental, portanto, é um assunto bastante difundido no mundo todo e alcança segmentos de esfera social, política e econômica. Esse assunto tem ganhado força com a inclusão de grandes potências preocupadas com a questão, especialmente com relação a temáticas em torno da poluição atmosférica, do desmatamento ou da escassez dos recursos hídricos. Nesse aspecto, qualquer que seja a problemática ambiental, o tópico tem tomado dimensões mundiais tais que conferências, políticas de incentivos, leis têm sido criadas, e pautas levantadas, a fim de se tentar controlar essas situações.

A questão da água já vem sido debatida com bastante seriedade em todo o mundo. A exemplo disso, no Brasil, foi criada a lei no 9433, mais conhecida como "das águas", isto é, uma política nacional de recursos hídricos, com o intuito de tutelar o gerenciamento para seu uso de forma mais controlada, em decorrência de sua escassez, já que os recursos hídricos tendem ao limite com sua má utilização. Logo, no artigo $2^{\underline{0}}$ da Lei $n^{\circ}$ 9.433/97 especifica-se, entre outros aspectos, a indispensabilidade de "Iassegurar à atual e às futuras gerações a necessária disponibilidade de água, em padrões de qualidade adequados aos respectivos usos”. Em suma, o dever da sustentabilidade tem se destacado de maneira positiva no que tange à consciência ambiental, em todos os

\footnotetext{
7 Disponível em: 〈http://www.planalto.gov.br/ccivil_03/leis/l9433.htm〉. Acesso em: 29 abr 2021
} 
parâmetros, desde preservação de recursos naturais até o aproveitamento de águas pluviais, passando inclusive por questões, como eficiência energética, a qual se encontra diretamente conectada à água, já que a maior forma de produção de energia elétrica, no Brasil, são as usinas hidrelétricas.

\subsection{QUESTÃO DA ESCASSEZ}

A escassez de água já é uma realidade em muitos locais no mundo todo. $\mathrm{O}$ crescimento acelerado da população mundial, o consumo intensivo e não sustentável dos recursos de natureza finita, a poluição dos mananciais, somados às mudanças climáticas são aspectos que provocam períodos mais prolongados de seca e, por sua vez, mais curtos e intenso de chuvas (DALSENTER, 20I6). Nesse viés, de acordo com o Mapa da Escassez no Mundo, de 2006, e com o relatório feito para Semana Mundial de Água, de 2006, em Estocolmo, na Suécia:

Um terço da população mundial sofre com algum tipo de escassez, sendo que existem dois tipos: a escassez econômica, gerada pela falta de infraestrutura de abastecimento e distribuição desigual e a escassez física quando os recursos hídricos da região não conseguem suprir a demanda, esta última típica de regiões áridas. (-PERONA, 20II, p. II,)

FIGURA I- Mapa de Escassez de Água no Mundo

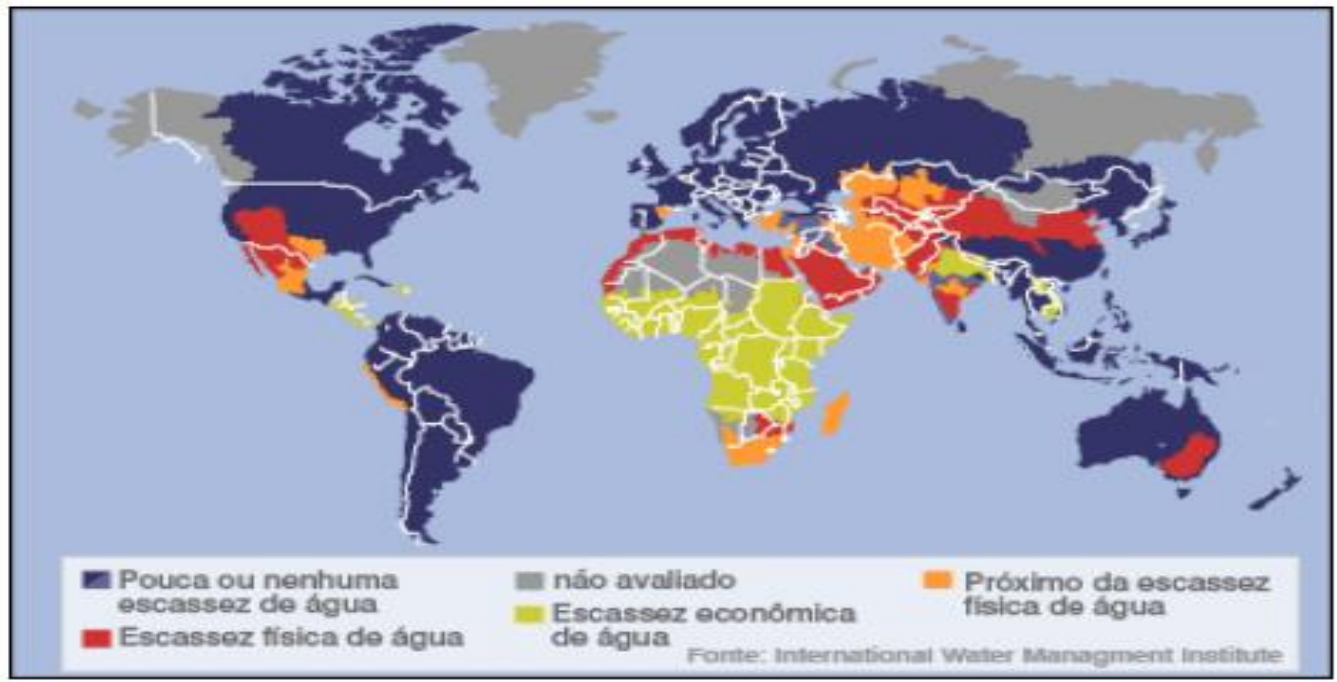

Fonte: International Water Managment Institute. Citado por BBC BRASIL, 2006 (In PERONA, 2011, p. 12). 
O Brasil é um país muito rico em recursos hídricos, com grande disponibilidade, mas com uma distribuição desigual, devido a sua grande extensão territorial. Conforme aponta (ANA, 2014):

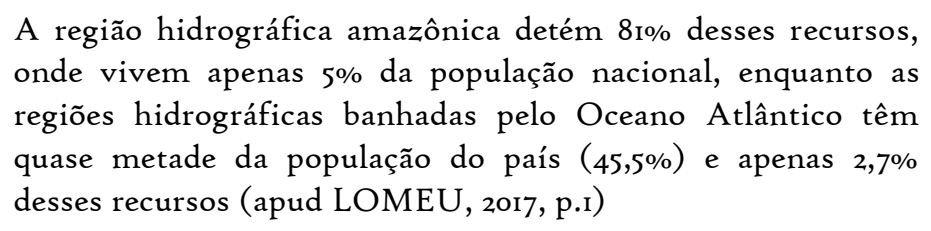

A seguir, na Figura 2, é possível observar que não só o Nordeste sofre com a escassez, uma vez que, em 2014, se pode constatar que a seca chegou também à região Sudeste, afetando a cidade local do estudo de caso, no caso, Juiz de Fora (MG).

FIGURA 2 - Níveis dos reservatórios de Juiz de Fora em setembro de 2015 e 2016
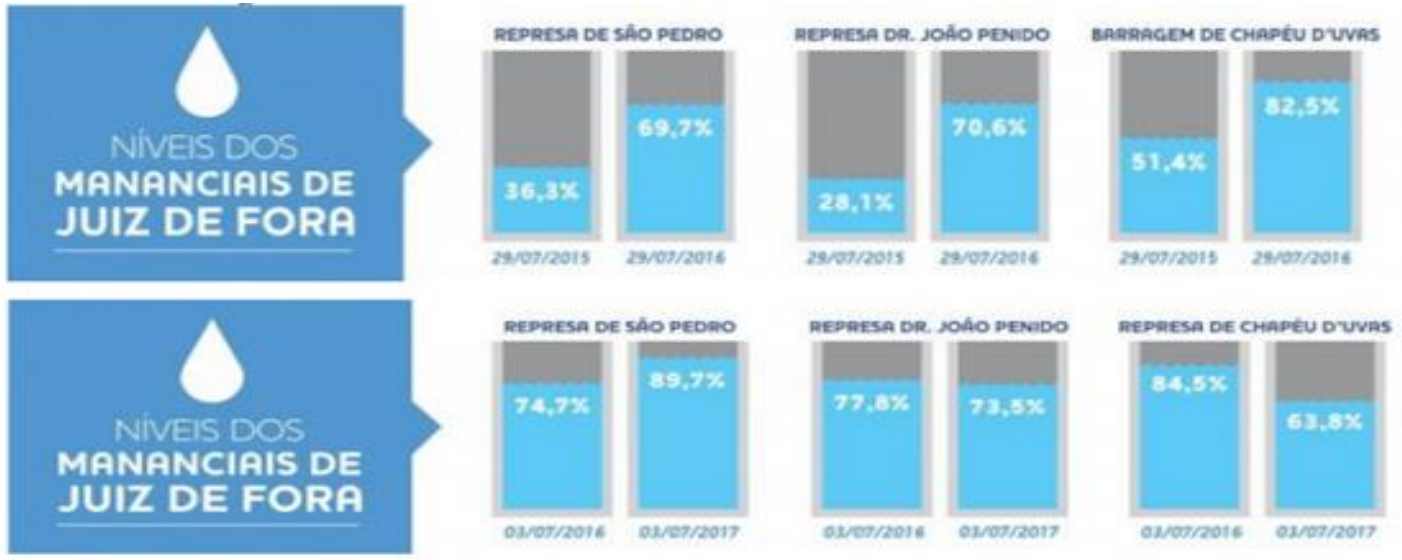

Fonte: (CESAMA, 2016. In: LOMEU, 2017, p.2).

No Brasil, mais precisamente nas regiões São Paulo, Rio de Janeiro, Espírito Santo e Paraná, foram manifestadas algumas iniciativas. Como destacado por Cosentino et al (2016, p.1245-1246), “Em Curitiba, o decreto municipal 293/o6 desde 2006 só fornece o alvará de construção para edificações que preveem um sistema de aproveitamento de água pluvial”.

Nos dias atuais, é evidente a importância da água no mundo. Cada vez mais se vê o valor deste recurso que, por sua abundância, era explorado sem preocupação com a possibilidade de uma futura escassez. Partindo do princípio de que a água é um recurso 
com extrema abundância no planeta, é natural que não haja preocupação com a sua falta.

FIGURA 3 - Distribuição da água no planeta Terra (tamanho - ver FIGURA 4)

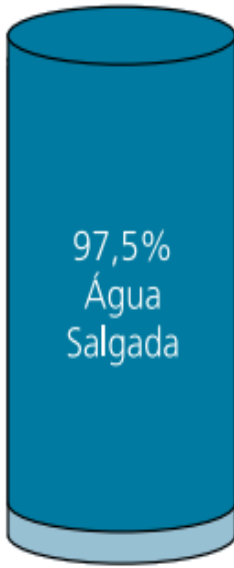

$2,5 \%$

Água Doce
TOTAL GLOBAL (Água Doce)

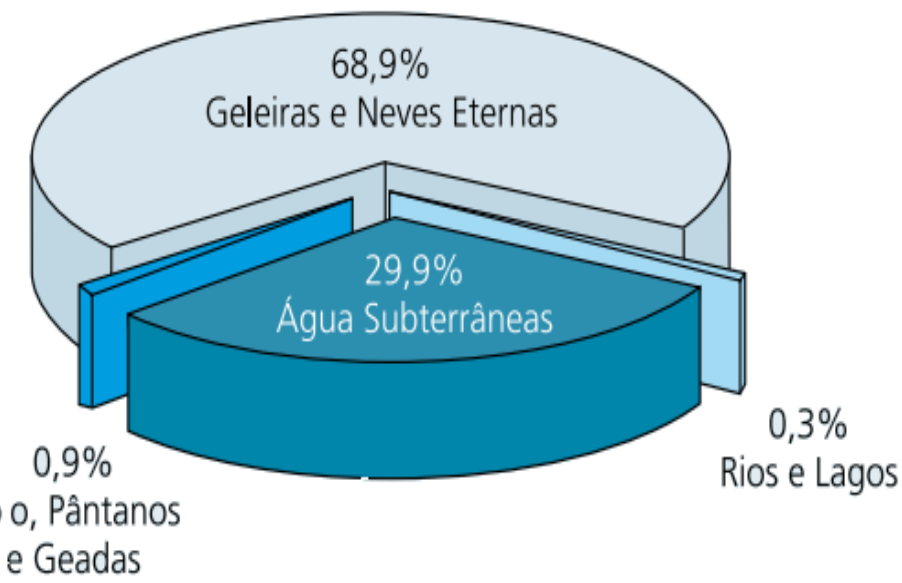

Fonte: Adaptado de SHIKLOMANOV, 1998, citado por TUNDISI, 2003 apud BRITO et al,2007.

O primeiro ponto é o tipo de água que se tem em abundância. A água doce é uma parcela muito pequena do total disponível no mundo e, dentro dessa pequena parcela, mais da metade se encontra na forma de geleiras. Ou seja, apesar de sua constatada abundância, a água acessível para uso é uma das menos disponíveis (BRITTO, 2007). Além disso, apesar de ser um recurso que passa por um ciclo, a instabilidade climática é um ponto de bastante importância para determinação do volume de água disponível aos humanos. Em tempos de seca, intensificam-se a evaporação da água e a falta da chuva, o que pode acarretar, em alguns lugares, extinção de rios e uma diminuição no nível de água em represas, reduzindo, então, a quantidade do recurso acessível naquele local.

Faz-se, portanto, necessária a redução do consumo exacerbado da água, bem como a sua reutilização quando possível, em razão da criação de uma forma alternativa para se combater o aumento da demanda pela água potável. Uma dessas fontes alternativas consistiria, por exemplo, no aproveitamento da água da chuva. Nesse aspecto, Mancuso \& Santos (2003) “afirmam que a população mundial só tende a crescer, agravando ainda mais a questão de escassez de recursos naturais, inclusive a 
água. Por isso é cada vez mais iminente o uso de tecnologias que busquem diminuir esses impactos” (apud LOMEU, 2017, p.4,).

Com o crescimento populacional, ocorre uma demanda maior pela água, contudo, essa existe em uma quantidade finita na natureza. Logo, a demanda em escala crescente entra em desacordo com a má utilização desse recurso.

\subsection{HISTÓRICO DO APROVEITAMENTO DA ÁGUA PLUVIAL}

Existem registros de que é milenar o aproveitamento da água de chuva, prática essa que, hoje, volta a chamar atenção. Em vários países, foram adotados métodos para captação, armazenamento e aproveitamento de água pluvial como método de se diminuírem os efeitos negativos apresentados pela falta do recurso hídrico, cada local com a sua destinação para o uso conforme a sua necessidade.

Steffen et al (2013) dizem que a captação de água pluvial foi usada por séculos para atender às necessidades de abastecimento da população. Ademais, atualmente, é considerada uma prática comum na Índia, África, Ásia e Austrália e em muitos outros lugares, para auxiliar, total ou parcialmente, as necessidades de abastecimento de água (apud DALNSENTER, 2016).

Comparado com outros países, no Brasil, o assunto ainda é considerado uma novidade, não chegando a ıoo anos desde o seu primeiro registro no país. Além disso, ainda é pouco disseminado e adotado o ato de se aproveitar a água da chuva, apesar de já se ter uma preocupação com a escassez do recurso (MAY, 2004).

\section{ATIVIDADES NAS QUAIS A ÁGUA PLUVIAL PODE SER APROVEITADA}

O aproveitamento das águas pluviais é uma das alternativas que vem sendo utilizada para combater a problemática da escassez, presente em vários lugares no mundo. As destinações para esse aproveitamento variam de acordo com a necessidade de cada local, bem como com a qualidade com que se encontra a água ao ser aproveitada. Apesar de existirem as atividades mais comuns para essa utilização, há também casos mais específicos, como, por exemplo, a utilização de água de chuva para consumo, que é possível, desde que haja um controle rigoroso da sua qualidade. Para isso, Goldenfum (2006, p.) cita: "deve-se destacar que usos que demandam água de qualidade elevada podem levar a custos incompatíveis com os benefícios do aproveitamento." 
Em um contexto geral, o aproveitamento se dá em irrigações (seja de gramados, seja em lavouras), limpeza de automóveis, abastecimento de lagos, fontes, piscinas e espelhos d'água em geral, descargas em sanitários, reservatórios para sistemas de proteção contra incêndio, limpeza de áreas, como passeios, garagens, entre outros.

\section{I REGIONALIDADES}

O Brasil é um país de grande extensão territorial e com uma alta diversidade cultural entre suas regiões. Isto posto, os costumes, que obviamente variam, também são aplicados à questão da água, seja em relação ao racionamento, seja pela sua reutilização ou pelo aproveitamento. Segundo ANA (ANO), apesar do grande volume de água doce disponível no país, em alguns locais, esse volume é muito pequeno, devido, entre alguns fatores, à questão climática, à má utilização ou, até mesmo, à densidade demográfica, cuja demanda é muito maior que a disponibilidade, gerando, assim, sua falta.

Cada região do país, portanto, possui disponibilidades hídricas bastante variáveis. No semiárido brasileiro, por exemplo, a necessidade da captação de água da chuva se faz extremamente necessária, bem como o seu armazenamento, para um posterior aproveitamento. Nessa região, os solos são, em sua maior parte, muito rasos, o que compromete a existência de aquíferos, além das altas temperaturas, que proporcionam altas taxas de evaporação. Em tempos de secas, a água armazenada nos períodos de chuva salva muitas famílias da escassez completa. Já em regiões como a amazônica, por sua vez, a quantidade de água disponível é suficiente para abastecer, com folga, a população desta região.

\subsection{ESTATÍSTICAS DO APROVEITAMENTO}

A escassez de água é um problema mundial, de tal forma que, de acordo com a ONU (Organização das Nações Unidas), a escassez de água afetará dois terços da população mundial até 2050 (ZATTA, 2014). Com a crescente preocupação da sua falta nos próximos anos, práticas sustentáveis vêm ganhando força, ainda que não sejam proporcionais ao tamanho do problema, a fim de frear a escassez de água. Países influentes, como Alemanha e Japão, já são referências internacionais no assunto aproveitamento de águas pluviais, o qual tem se tornado uma importante alternativa 
para contornar a questão da escassez. (MACHADO, 2012).

No Brasil, existem estudos que indicam que o valor a ser pago para a instalação de um sistema hidráulico que auxilie o abastecimento, para uso não potável, é bastante compensatório. Dessa forma captar, armazenar e aproveitar a água que incide sobre os telhados, através da precipitação é, comprovadamente, não só um investimento de retornos positivos para o meio ambiente, como também economicamente. $\mathrm{O}$ fato de se aproveitar da água de chuva, então, pode apresentar vantagens econômicas, segundo May (2004), cujos índices podem ser superiores a 50\%, tendo em vista que nem em todos os usos existe a necessidade de que água seja potável. Para isso, é possível citar as descargas sanitárias, que são os grandes consumidores de água em residências, e são um dos locais indicados para o uso de águas pluviais.

\subsection{TÉCNICAS DE APROVEITAMENTO}

Para que haja o aproveitamento de águas pluviais, é necessário que essas sejam captadas, tratadas e armazenadas. Nesse viés, começa-se com um estudo dos índices pluviométricos da região para determinar nível de chuva que incide no local. O segundo passo é determinar qual o tamanho da área de contribuição (do telhado, por exemplo). Para encerrar essa primeira etapa de maneira bastante resumida, faz-se uma projeção da quantidade de água que será demandada nas devidas utilizações, para, assim, determinar qual será o tamanho do reservatório que a armazenará.

Outro passo importante é enumerar as utilizações para que se obtenha o nível de tratamento necessário, tendo em vista que não se trata de uma água potável. Independente desse fator, um sistema de filtração sempre é recomendado, para que seja separada a água de alguns dejetos, como penas e folhas, que são bastante comuns de serem encontrados em telhados. Além da filtração é recomendado o descarte dos primeiros milímetros de chuva, levando em consideração que alguns detritos presentes no telhado podem ser diluídos na água e acabar passando pelo processo de filtração. $O$ tratamento da água do telhado em relação ao tempo de chuva a ser estimado para descarte varia em função das condições do próprio telhado, bem como do tempo de estiagem, já que, quanto maior o tempo sem chuva, maior será a quantidade de impurezas presentes no telhado. Por fim, recomenda-se evitar a exposição do reservatório de armazenamento à luz solar, com o intuito da não proliferação de micro- 
organismos e, ainda, da utilização de artifícios que difiram da instalação de águas pluviais e da instalação de água potável, com a finalidade de se evitar ligações cruzadas e usos indevidos.

FIGURA 4 - Esquema do sistema de aproveitamento de água pluvial

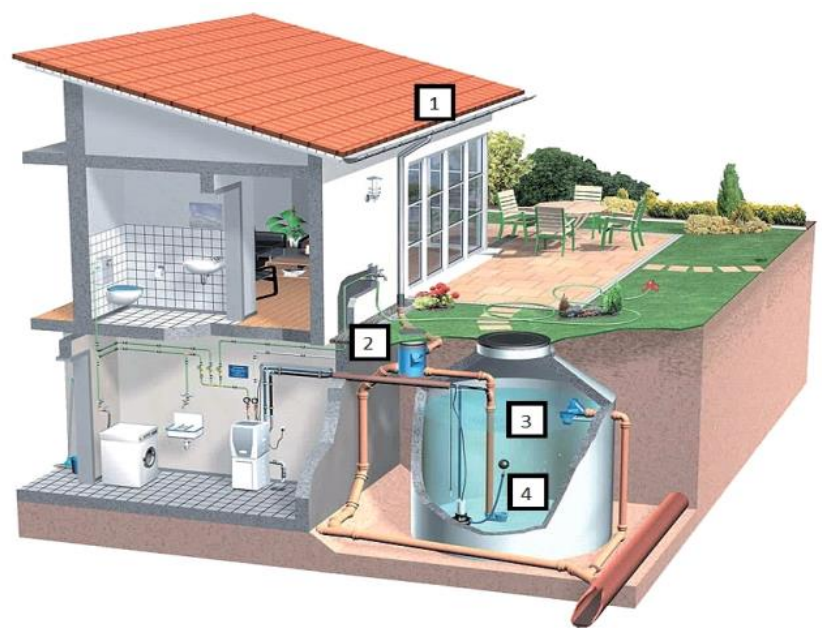

\section{ESTUDO DE CASO}

Uma residência de alto padrão, localizada na cidade de Juiz de Fora (MG), possui o sistema de aproveitamento de água pluvial para realizar algumas atividades em suas dependências. Será feita uma avaliação em relação ao sistema já dimensionado, a fim de se obter alguns dados para concluir sobre a viabilidade da alternativa do uso de água de chuva.

\section{I V OLUMES "PRODUZIDOS" DE ÁGUA PLUVIAL}

Para que haja uma utilização da água pluvial, é necessário que ela seja previamente captada, tratada e armazenada em reservatórios (cisternas), conformo foi apresentado anteriormente. Além disso, como apontado, o volume do reservatório relaciona-se com os volumes de água demandada e de chuva a ser captado. Existem, dessa maneira, alguns métodos matemáticos utilizados para se estimar o volume de chuva possível de ser recolhido.

Para isso, Palhares (2016) afirma que a forma de se obter resultados mais assertivos é através de fórmulas as quais se baseiam em dados pluviométricos que são 
registrados por um histórico de acontecimentos. Nesse aspecto, a NBR 15527 (2007) estabelece que o volume de água que poderá ser captado se dá pela equação I:

$V_{\text {CHUVA }}=A x I x C x E$ (equação I)

$\mathrm{V}_{\text {CHUVA }}=$ Volume de chuva a ser captado $\left(\mathrm{m}^{3}\right)$

$\mathrm{A}=$ Área do telhado $\left(\mathrm{m}^{2}\right)$

$\mathrm{I}=$ Índice pluviométrico $(\mathrm{m} / \mathrm{mês})^{8}$

$\mathrm{C}=$ Coeficiente de escoamento superficial da cobertura $^{9}$

$\mathrm{E}=$ Eficiência do filtro

A residência analisada possui uma área de cobertura de $373 \mathrm{~m}^{2}$, e o índice pluviométrico da região é demonstrado no Quadro I.

\begin{tabular}{cccc}
\multicolumn{2}{c}{ QUADRO I - Índice pluviométrico de Juiz de Fora - MG } \\
Més & Minima $\left({ }^{\circ} \mathrm{C}\right)$ & Máxima $\left({ }^{\circ} \mathrm{C}\right)$ & Precipitação $(\mathrm{mm})$ \\
Janeiro & $20^{\circ}$ & $28^{\circ}$ & 365 \\
Fevereiro & $20^{\circ}$ & $29^{\circ}$ & 270 \\
Março & $20^{\circ}$ & $28^{\circ}$ & 261 \\
Abril & $18^{\circ}$ & $27^{\circ}$ & 121 \\
Maio & $16^{\circ}$ & $24^{\circ}$ & 63 \\
Junho & $14^{\circ}$ & $23^{\circ}$ & 31 \\
Julho & $13^{\circ}$ & $23^{\circ}$ & 33 \\
Agosto & $14^{\circ}$ & $24^{\circ}$ & 41 \\
Setembro & $15^{\circ}$ & $25^{\circ}$ & 96 \\
Outubro & $17^{\circ}$ & $26^{\circ}$ & 168 \\
Novembro & $19^{\circ}$ & $27^{\circ}$ & 286 \\
Dezembro & $19^{\circ}$ & $27^{\circ}$ & 380 \\
Fonte: (CLIMATEMPO & $\mathrm{ANO})$ & &
\end{tabular}

Segundo Rocha et al (2019), os filtros possuem uma capacidade de retenção de partículas de até $0,28 \mathrm{~mm}$, e o valor médio da eficiência para captação do fluido se dá torno de $90 \%$. Com base nessa informação e de posse dos outros dados já mencionados, é possível obter os valores estimados para o potencial volume de chuva a ser captado, os quais são apresentados no Quadro a seguir por meio da equação I.

\footnotetext{
${ }^{8}$ Se os dados apresentados estiverem em milímetros, dividir por i.ooo (mil) para obter a unidade desejada. 9 Segundo Palhares (2016), o valor de o,8o é sugerido independente do material a ser utilizado na cobertura.
} 
QUADRO 2 - Valores estimados para o potencial volume de chuva captado

\begin{tabular}{|l|l|}
\hline MÊS & Potencial V $_{\text {CHUVA a ser captado }}$ \\
\hline JANEIRO & $98,02 \mathrm{~m}^{3}$ \\
\hline FEVEREIRO & $72,51 \mathrm{~m}^{3}$ \\
\hline MARÇO & $70,09 \mathrm{~m}^{3}$ \\
\hline ABRIL & $32,50 \mathrm{~m}^{3}$ \\
\hline MAIO & $16,92 \mathrm{~m}^{3}$ \\
\hline JUNHO & $8,33 \mathrm{~m}^{3}$ \\
\hline JULHO & $8,86 \mathrm{~m}^{3}$ \\
\hline AGOSTO & $\mathrm{II}, 01 \mathrm{~m}^{3}$ \\
\hline SETEMBRO & $25,78 \mathrm{~m}^{3}$ \\
\hline OUTUBRO & $45,12 \mathrm{~m}^{3}$ \\
\hline NOVEMBRO & $76,8 \mathrm{I} \mathrm{m}^{3}$ \\
\hline DEZEMBRO & $102,05 \mathrm{~m}^{3}$ \\
\hline
\end{tabular}

Os valores obtidos acima são analisados conforme a necessidade de abastecimento pelo sistema, ou seja, é feito um estudo sobre a demanda da residência por essa água, para, assim, ser possível estabelecer o volume necessário do reservatório. É importante destacar que, entre os critérios do reservatório, seja estabelecido um volume reservado para atender às necessidades da residência em períodos não chuvosos. Para isso, não se deve deixar de analisar a viabilidade econômica do sistema, já que, para Palhares (2016), o custo do reservatório impacta de 50\% a $85 \%$ no valor do sistema.

\subsection{DESTINAÇÃO (PARA QUAIS USOS?)}

A utilização do recurso captado pode se dar de diversas formas, cabendo o devido tratamento ser feito de acordo com a sua destinação. Na residência do presente estudo de caso, será aproveitada a água de chuva em torneiras no exterior da casa, com a finalidade de atender a três demandas: irrigação de jardim, lavagem de carro e limpeza de calçada.

Para se obter um valor de volume estipulado para estas demandas, Palhares (2016, p.) apresenta uma equação bem simples, que consiste em um somatório de volumes diários demandados, multiplicado por um fator 30 (o qual equivale à quantidade de dias presentes em um mês). A aplicação dessa formulação resulta em um valor de volume demandado mensal, conforme é demonstrado na equação 2.

$\mathrm{V}_{\text {DEMANDADO }}=\sum \mathrm{D} \times 30$ (equação 2$)$ 
$\mathrm{V}_{\text {DEMANDADO }}=$ Volume demandado pela residência $\left(\mathrm{m}^{3} / \mathrm{mês}\right)$

$\Sigma \mathrm{D}=$ Somatório das demandas da residência $\left(\mathrm{m}^{3} / \mathrm{dia}\right)$

$30=$ Quantidade de dias em um mês

De acordo com as demandas citadas para essa residência, é necessário chegar em um valor de volume de água para atender a tais necessidades. O site Rede Agronomia (2017) expõe que, para irrigação de jardins, o volume de água a ser utilizado varia de acordo com a latitude e com o clima em que a residência se encontra. Porém, em média, o valor não ultrapassa 5 litros $/ \mathrm{m}^{2}$.

Quando se trata da lavagem de carros, a quantidade de água gasta estabelecida pela DEMAE (2017) é de 56o litros com a torneira aberta em meia volta e por um tempo determinado de 30 minutos. Além desse parâmetro, o departamento ainda fornece a quantidade de água necessária para o quesito limpeza de calçadas (o volume de água gasto seria equivalente a 279 litros por um período de 15 minutos de utilização). Vale ressaltar que, em ambas as considerações, os valores foram estimados com a utilização de uma mangueira ao invés de baldes, o que diminuiria consideravelmente o consumo.

A residência estudada na presente pesquisa possui uma área verde de $336 \mathrm{~m}^{2}$ e uma calçada de $52 \mathrm{~m}^{2}$. Além disso, os proprietários possuem dois carros os quais são lavados uma vez por semana. Logo, baseando-se nas informações descritas e adaptando-as aos valores bases na equação 2, tem-se:

1) Demanda do jardim: será prevista a rega 2 vezes por semana $\left(2 \times 51 / \mathrm{m}^{2} \times 336 \mathrm{~m}^{2}\right.$ $=3360$ litros $/$ semana $)$.

2) Demanda da calçada: serão considerados, para lavar $52 \mathrm{~m}^{2}$ de calçada, 15 minutos e a mesma será lavada I vez por semana $=279$ litros/semana.

3) Demanda dos carros: será considerado o tempo médio de 30 minutos para lavar cada carro e eles serão lavados $\mathrm{I}$ vez por semana $(2$ carros $\mathrm{x} 560$ litros $=$ II 20 litros/semana).

O somatório das demandas é feito e, em seguida, o resultado é aplicado por meio da equação 2, conforme apresentado a seguir:

$\Sigma \mathrm{D}=3360+279+\mathrm{II20}=4759$ litros $/$ semana ou $0,68 \mathrm{~m}^{3} / \mathrm{dia}$

$\mathrm{V}_{\text {DEMANDADO }}=0,68 \times 30=20,4 \mathrm{~m}^{3} /$ mêsPortanto, $\mathrm{o}$ volume de água pluvial que será gasto para atender as atividades previstas é de $20,4 \mathrm{~m}^{3}$ por mês. 


\subsection{RELAÇÃO VOLUMES "PRODUZIDOS" X "NECESSÁRIOS"}

A eficiência do sistema de aproveitamento da água de chuva está relacionada diretamente ao volume demandado e ao volume captado, obtendo-se o valor de volume demandado igual a 20,4 $\mathrm{m}^{3}$ mensais. Ao se verificar o Quadro 3, apresentado a seguir, é possível concluir que a quantidade de água captada mensalmente no período de setembro até abril fornece ao sistema um funcionamento perfeito quanto às demandas da residência estudada. Entre os meses de maio até agosto, por sua vez, nota-se que o volume captado não seria suficiente para atender as demandas da residência, de forma que essa precisaria utilizar uma reserva de outros meses para suprir a falta de chuva neste período.

O sistema funciona de forma autônoma se o volume de água reservado nos meses chuvosos for suficiente para abastecer as demandas nos meses de "seca". No Quadro a seguir, é demonstrada uma relação da quantidade de água que seria necessário ser reservada para uso em meses menos chuvosos. Estes valores foram obtidos através da equação 3, apresentada abaixo, denominada de $\mathrm{V}_{\text {FALTANTE}}$. Vale ressaltar que, em caso de resultados negativos, entende-se que o volume de chuva atendeu à demanda e não existe um volume faltante.

$\mathrm{V}_{\text {FALTANTE }}=\mathrm{V}_{\text {DEMANDADO }}-\mathrm{V}_{\text {CHUVA }}($ equação 3)

QUADRO $_{3}$ - Relação Vchuva x Vfaltante

\begin{tabular}{|c|c|c|}
\hline MÊS & $\mathrm{V}_{\text {CHUVA }}$ & V $_{\text {FALTANTE }}$ \\
\hline JANEIRO & $98,02 \mathrm{~m}^{3}$ & - \\
\hline FEVEREIRO & $72,51 \mathrm{Im}^{3}$ & - \\
\hline MARÇO & $70,09 \mathrm{~m}^{3}$ & - \\
\hline ABRIL & $32,50 \mathrm{~m}^{3}$ & - \\
\hline MAIO & $\mathrm{I} 6,92 \mathrm{~m}^{3}$ & $3,48 \mathrm{~m}^{3}$ \\
\hline JUNHO & $8,33 \mathrm{~m}^{3}$ & $12,07 \mathrm{~m}^{3}$ \\
\hline JULHO & $8,86 \mathrm{~m}^{3}$ & $\mathrm{II}, 54 \mathrm{~m}^{3}$ \\
\hline AGOSTO & II,OI $\mathrm{m}^{3}$ & $9,39 \mathrm{~m}^{3}$ \\
\hline SETEMBRO & $25,78 \mathrm{~m}^{3}$ & - \\
\hline OUTUBRO & $45,12 \mathrm{~m}^{3}$ & - \\
\hline NOVEMBRO & $76,81 \mathrm{~m}^{3}$ & - \\
\hline DEZEMBRO & $102,05 \mathrm{~m}^{3}$ & - \\
\hline
\end{tabular}


Nos meses em que o volume de chuva é insuficiente para as demandas, por serem consecutivos, é preciso que, antecedendo o primeiro mês faltante (Abril), o volume armazenado seja igual ou superior à soma dos volumes faltantes, juntamente com o volume da demanda mensal. Para enfatizar o raciocínio, tem-se a equação 4.

$\mathrm{V}_{\mathrm{ABRIL}}=\sum \mathrm{V}_{\mathrm{FALTANTE}}+\mathrm{V}_{\text {DEMANDADO }}($ equação 4$)$

O resultado do somatório se dá pelo valor de $36,48 \mathrm{~m}^{3}$ de volume faltante, o qual é dividido por todos os outros meses que atingiram suas metas. Se for armazenado 4,56 $\mathrm{m}^{3}$ a mais em cada um destes 8 meses, encontra-se o volume necessário para atender à equação 4, além disso, toda a demanda nos meses com piores índices de chuva será obtida. Sendo assim, o volume do reservatório é dado pela soma do volume demandado mensal com a taxa extra de reserva para os meses com menos chuva, totalizando, dessa maneira, um volume mínimo de aproximadamente $25 \mathrm{~m}^{3}$.

Vale ressaltar, porém, que, apesar de o volume do reservatório ser estimado para atender a todos os meses, nem sempre esse resultado é consolidado para o projeto, porque vários fatores influenciam na decisão, inclusive os econômicos. Nessa conjuntura, Palhares (2016) considera outro fator bastante importante na tomada de decisão o qual, em alguns casos, sobressai, até mesmo, o aspecto econômico: a questão da disponibilidade hídrica. Em lugares com condições de escassez, portanto, a decisão não deve ser levada apenas para o âmbito financeiro.

\subsection{ECONOMIA"S" GERADAS}

A água é um produto que possui um valor econômico, e o uso racional desse recurso traz resultados positivos para o meio ambiente e para a situação financeira de quem o pratica. No cenário econômico, o aproveitamento de água pluvial é um investimento, já que, ao aproveitar a água de chuva, não é preciso pagar pelo abastecimento por parte da concessionária.

Seguindo este raciocínio, a economia advinda da implantação do sistema está intimamente relacionada aos custos tarifários da água potável fornecida pela empresa local. Dessa forma, basta comparar o volume de água que se é aproveitado mensalmente e analisar o quanto se pagaria para ter acesso ao mesmo volume, o qual seria fornecido pela companhia responsável. 
No caso de Juiz de Fora, a concessionária local é a Companhia de Saneamento Municipal (Cesama). Em seu site, é encontrada uma planilha a qual que simula o valor a ser pago por um determinado consumo. A planilha mencionada é apresentada abaixo, por meio da Figura 5. Nela, pode-se notar o valor de 2i $\mathrm{m}^{3}$ de água utilizada, por aproximação do volume demandado de $20,4 \mathrm{~m}^{3}$.

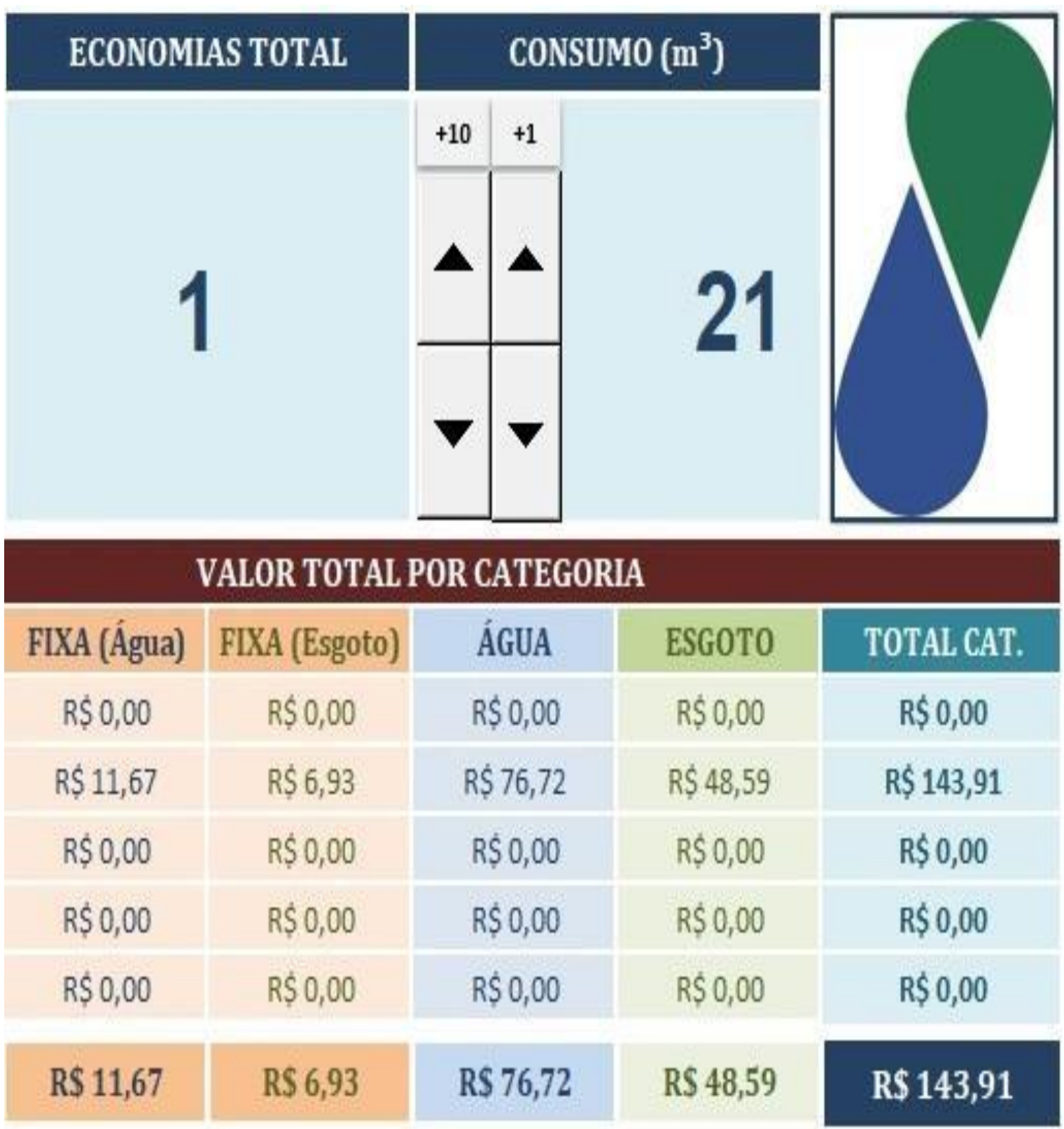

Fonte: CESAMA. ${ }^{\circ}$

${ }^{10}$ Disponível em: <http://www.cesama.com.br/>. Acesso em: 13 maio 2021 
Interpretando a figura, conclui-se que seriam gastos $\mathrm{R}_{\$ 143,91}$ por mês com a utilização de água potável. Enquanto isso, o sistema de aproveitamento, em seu perfeito funcionamento, zera qualquer custo relacionado ao abastecimento após algum tempo, mais especificamente, no momento em que a somatória mensal desse valor atingir o montante investido. $\mathrm{O}$ que seria gasto mensal, então, depois de alguns meses, passa a ser lucro.

\subsection{BENEFÍCIOS}

O aproveitamento de águas pluviais traz resultados econômicos satisfatórios por evitar a utilização da água potável em atividades que não necessitam de uma água com um controle de qualidade tão elevado. Porém, esse não é o único benefício presente na adoção do sistema.

A captação de água de chuva, seguida do seu armazenamento, gera um alívio nas galerias pluviais, podendo, até mesmo, cooperar para que não haja um transbordamento seguido de inundação de uma área, por exemplo. Contudo, para se ter resultados tão satisfatórios a tal ponto, é necessário um aglomerado de sistemas em uma região, e não apenas algumas poucas unidades isoladas, como ainda é presenciado nos dias de hoje.

Outro ponto positivo de se adotar o sistema está relacionado à questão ambiental. A escassez de água já está presente em alguns lugares do mundo, entre os quais no Brasil, especialmente em determinadas épocas do ano caracterizadas pela seca. Ao se valer, por fim, do aproveitamento de água pluvial, a consciência ambiental é também demonstrada, pois ocorre um uso racional desse recurso tão essencial que pode vir a faltar.

\section{CONSIDERAÇÕES FINAIS}

A água é um bem essencial para o desenvolvimento socioeconômico da humanidade e, por ter sido considerada abundante na natureza, por décadas foi explorada sem a preocupação de que o consumo desenfreado deste recurso poderia resultar em futuro problema de escassez de água. E mesmo sendo um recurso imprescindível, nunca se teve tanta preocupação com relação à sua possível falta.

Diante deste contexto, é que se insere o aproveitamento de água pluvial para fins não potáveis, com a finalidade de verificar uma possível redução do uso de água potável 
em atividades corriqueiras, como irrigação de jardim, lavagem de carro e limpeza de calçada.

Para que haja o aproveitamento de águas pluviais, de uma forma resumida, é necessário que essas sejam captadas, tratadas e armazenadas. Aliado a isso, é necessário um estudo dos índices pluviométricos da região para determinar o nível de chuva que incide no local. Determinar qual o tamanho da área de contribuição (do telhado, por exemplo), a projeção da quantidade de água que será demandada nas devidas utilizações, para, assim, determinar qual será o tamanho do reservatório que a armazenará.

A eficiência do sistema de aproveitamento da água de chuva está relacionada diretamente ao volume demandado e ao volume captado. Do item 5.2 conclui-se que para a residência em estudo, o volume demandado para atender as atividades mencionadas no mesmo item, será de $20,4 \mathrm{~m}^{3}$ ao mês.

No quadro 3 (item 5.3), observa-se que a quantidade de água captada mensalmente do período de setembro a abril pelo sistema atende ao volume demandado. Já nos meses de maio a agosto capta-se uma menor quantidade de água de chuva. Sendo necessário utilizar uma reserva de outros meses para suprir a falta de chuva neste período (conforme a equação 4).

Analisando-se a figura 5, é possível identificar que para serem fornecidos $21 \mathrm{~m}^{3} \mathrm{de}$ água pela concessionária local, será cobrado o valor de $\mathrm{R}$ \$ I43,9I. Enquanto o sistema de aproveitamento, em seu perfeito funcionamento anula qualquer gasto com abastecimento.

O sistema de aproveitamento de água é bastante satisfatório, a não utilização de água potável em atividades que não demandam um controle de alta qualidade, traz retornos positivos para o meio ambiente. A captação de água de chuva, gera um alívio nas galerias pluviais, podendo ainda cooperar para que não haja transbordamento, seguindo de inundação de uma área. No cenário econômico, é um investimento, já que, ao aproveitar a água de chuva, não é preciso pagar pelo abastecimento por parte da concessionária.

Contudo, vale ressaltar que, para se ter resultados eficientes, é necessário um aglomerado de sistemas em uma região, e não apenas algumas poucas unidades isoladas, como ainda é presenciado nos dias de hoje. 


\section{REFERÊNCIAS}

ANA. AGÊNIA NACIONAL DE ÁGUAS. Conjuntura dos Recursos Hídricos no Brasil - Encarte Especial sobre a Crise Hídrica, 2014. Disponível em: $\langle$ http://conjuntura.ana.gov.br/docs/crisehidrica.pdf $\rangle$. Acesso em:.

BEZERRA, Juliana. Revolta da Vacina. In: TODA MATÉRIA, s./d. Disponível em: <https://www.todamateria.com.br/revolta-davacina/\#: :text=A\%2oRevolta\%2oda\%2oVacina\%2ofoi,Janeiro\%2C\%2oem\%2onovembr o\%2ode\%201904>. Acesso em:

BRITO, LT de L.; SILVA, A. de S.; PORTO, Everaldo R. Disponibilidade de água e a gestão dos recursos hídricos. Embrapa Semiárido. In: Nome dos organizadores. Nome da obra do livro científico. Local: Editora, 2007. Número de páginas do capítulo.

COSENTINO, Livia Tavares; BORGES, Marcos Martins. Benefícios da captação de água pluvial para a gestão urbana de recursos hídricos. In: SBEı6 BRAZIL \& PORTUGAL. Sustainable Urban Communities towards a Nearly Zero Impact Built Environment. 2016.

Disponível em: < http://civil.uminho.pt/sber6_Brazil_Portugal/. Acesso em: 20 Maio 2021.

DALSENTER, Marta Elisa Vettori et al. Estudo de potencial de economia de água potável por meio do aproveitamento de água pluvial em um condomínio residencial multifamiliar localizado em Florianópolis-SC. 2016.

ESCOLA BRITANNICA. Civilização. Disponível em: <https://escola.britannica.com.br/artigo/civiliza\%C3\%A7\%C3\%A30/480992\#: :text=A s\%20civiliza\% $\mathrm{C}_{3} \% \mathrm{~A}$ 7\% $\mathrm{C}_{3} \% \mathrm{~B}_{5}$ es\%20surgiram\%2oinicialmente\%2onos,onde\%20atualme nte\%20\% 3 3\%A9\%200\%20Iraque $>$. Acesso em: $\mathrm{xx} / \mathrm{xx} / \mathrm{xx}$.

GOMES, Natan Panucci. Aproveitamento de água pluvial para fins não potáveis em uma residência de alto padrão na cidade de Maringá-PR. Orientador: Moacir Feba Tetila. 2018. I8f. Trabalho de Conclusão de Curso (Graduação em Engenharia Civil). UNICESUMAR, Maringá, 20I8. Disponível em: <>. Acesso em: 2r Maio 202I. 
LOMEU, Alice Azevedo. Aproveitamento de águas pluviais: Avaliação preliminar do custo-benefício da implementação de um sistema na Universidade Federal de Juiz de Fora -MG. Orientador: . 2017. f . Trabalho de Conclusão de Curso (Engenharia Ambiental).

Universidade Federal de Juiz de Fora, Juiz de Fora, 2017. Disponível em: <>. Acesso em: MAY, Simone. Estudo da viabilidade do aproveitamento de água de chuva para consumo não potável em edificações. Orientador: . 2004. f. Dissertação de Mestrado (Area de Concentração). Universidade de São Paulo, São Paulo, 2004. Disponível em: <>. Acesso em:

PERONA, Jean François. Eficiência do uso da água nas edificações. Orientador: José Claudio Nogueira Vieira. 20II. 49f. Monografia de Especialização (Engenharia Civil). Universidade Federal de Minas Gerais, Belo Horizonhte, 20II. Disponível em: <>. Acesso em: 2I Maio 202I.

PLANALTO. Mensagem de veto_inciso XIX do art. 2I da Constituição Federal (Vide Decreto de is de setembro de 2010). Disponível em: 〈http://www.planalto.gov.br/ccivil_03/leis/19433.htm.>._Acesso em:

SELANDER, Margareta; VALDIVIA, Luisa. Consumo sustentável: Manual de educação. Brasília: Consumers International/ MMA/ MEC/ IDEC, 2005. Disponível em: 〈http://portal.mec.gov.br/dmdocuments/publicacao8.pdf〉. Acesso em: 20 Maio 2021.

SIQUEIRA CAMPOS, Marcus André. Aproveitamento de água pluvial em edifícios residenciais multifamiliares na cidade de São Carlos. Orientador: . 2004. f. Dissertação de Mestrado (). Universidade Federal de São Carlos, São Carlos, 2004. Disponível em: <>. Acesso em:

SOUZA, Juliana et al. Aproveitamento de água de chuva para usos não potáveis na Universidade Severino Sombra. Teccen. Local, v. 9, n. I, p. 35-46. jan./jun 2016. Disponível em: <>. Acesso em: 
STEFFEN, J. et al. Water supply and stormwater management benefits of residential rainwater harvesting in U.S. cities. Journal of The American Water Resources Association. Local, v. , n. , 2013, p.810-824. Disponível em: <>. Acesso em:.

TOMAZ, P. Economia de água para empresas e residências. Um estudo atualizado sobre o uso racional da água. São Paulo: Navegar, 200I

ZATTA, Samara de Matia; DUARTE, Caroline Fernanda; SOUSA, Renata Esser; RUSCHEL, Andressa Carolina. A captação e utilização de água pluvial em residências como alternativa para fins não potáveis. 6o Simpósio de Sustentabilidade $e$ Contemporaneidade nas Ciências Sociais. Local, 2018. Disponível em: <>. Acesso em: 